MEDICAL PRACTICE

\title{
Medical certification of death in South Africa - moving forward
}

\author{
E H Burger, P Groenewald, A Rossouw, D Bradshaw
}

Lené Burger is a forensic pathologist in the Division of Forensic Medicine, Faculty of Medicine and Health Sciences, Stellenbosch University, and the Western Cape Forensic Pathology Service. Pam Groenewald, Stacey Rossouw and Debbie Bradshaw represent the Burden of Disease Research Unit at the Medical Research Council, Parow, Cape Town, South Africa. The authors compiled the training materials and provided the training for the intervention described in this article. They have published extensively regarding causes of death and the death notification form.

Corresponding author: E H Burger (ehb@sun.ac.za)

Despite improvements to the Death Notification Form (DNF) used in South Africa (SA), the quality of cause-of-death information remains suboptimal. To address these inadequacies, the government ran a train-the-trainer programme on completion of the DNF, targeting doctors in public sector hospitals. Training materials were developed and workshops were held in all provinces. This article reflects on the lessons learnt from the training and highlights issues that need to be addressed to improve medical certification and cause-of-death data in SA. The DNF should be completed truthfully and accurately, and confidentiality of the information on the form should be maintained. The underlying cause of death should be entered on the lowest completed line in the cause-of-death section, and if appropriate, HIV should be entered here. Exclusion clauses for HIV in life insurance policies with Association of Savings and Investments South Africa companies were scrapped in 2005. Interactive workshops provide a good learning environment, but are logistically challenging. More use should be made of online training resources, particularly with continuing professional development accreditation and helpline support. In addition, training in the completion of the DNF should become part of the curriculum in all medical schools, and part of the orientation of interns and community service doctors in all facilities.

S Afr Med J 2015;105(1):27-30. DOI:10.7196/SAMJ.8578

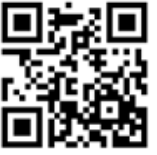

In recent years, the death notification form (DNF) used in South Africa (SA) has gone through some major changes. At the dawn of democracy in the country, two different forms were used: the BA-679 and the BI-12. Little statistical information was collected on these forms, and the causes of death were not entered in the format prescribed by the World Health Organization (WHO). These problems were remedied in the BI-1663, a 2-page form introduced in $1998 .^{[1]}$ About 12 years later, the form was revised to the DHA-1663, to capture more demographic information, provide improved security measures to prevent identity fraud, and include a perinatal cause-of-death section for stillbirths and deaths within the first week of life.

Despite improvements to the form, the quality of cause-of-death information in SA remains suboptimal. ${ }^{[2,3]}$ In a recent evaluation, Joubert et al. ${ }^{[4]}$ found that the extent to which certification and coding of conditions accurately reflected causes of death was unsatisfactory. Despite the high prevalence of HIV (estimated to be $12.2 \%$ in 2012), ${ }^{[5]}$ according to official statistics, HIV only accounted for $3.4 \%$ of deaths nationally in $2010,{ }^{[6]}$ indicating gross under-reporting. In the same year, tuberculosis (11.6\%), influenza and pneumonia (7.2\%) and intestinal infectious diseases (5.0\%), all known complications of HIV infection, were the leading causes of death, and 'Other viral diseases, not elsewhere classified' (relating to 'retroviral disease', a euphemism for HIV) also featured in the top ten causes of death. ${ }^{[6]}$ This reflects the continued reluctance of many doctors to report HIV as a cause of death.

There are other quality concerns in the statistical information. In $2010,23.9 \%$ of deaths were reported as due to ill-defined or unknown natural causes. These include cardiorespiratory arrest, heart failure, hypoxia and other nonspecific causes of death, which do not provide information useful for planning prevention strategies. ${ }^{[6]}$ There was also much uncertainty about the manner of death for injury deaths, as there is no field for such information on the DNF, and doctors often fail to report it in the cause-of-death section. This makes it difficult to determine whether the injuries were caused by accidents, homicide or suicide. Following international coding practices, deaths from gunshot injuries of undetermined intent are currently coded as accidents, thus under-representing homicides in Statistics South Africa (Stats SA) data, and so misrepresenting the real burden of homicide deaths. ${ }^{[6]}$

\section{Train-the-trainer intervention}

Recognition of the inadequacies of the SA cause-of-death data for monitoring the health status of the nation led to the formation of a task team in 2010/2011 to build capacity for ongoing medical certification training in the health services, among other system-strengthening activities. ${ }^{[2]}$ The task team comprised members representing Stats SA, the national Department of Health and the national Department of Home Affairs. Through Stats SA, a team (comprising the authors) was appointed to develop a train-the-trainer programme targeting certifiers/doctors in public sector hospitals. The brief was:

- To compile a guideline for medical doctors for completing the DHA-1663

- To prepare a 2-day training programme, with the aim of training 'master trainers' at facilities in all provinces

- To prepare a presentation for master trainers to use when training their colleagues

- To prepare a flyer with summary guidelines on DNF completion.

An important aim of the training was to help doctors focus on the underlying cause of death, defined by the $\mathrm{WHO}$ as: $(i)$ the disease 
or injury that initiated the train of morbid events leading directly to death; or (ii) the circumstances of the accident or violence that produced the fatal injury. ${ }^{[7]} \mathrm{A}$ flow diagram indicating the thought process for completing a cause-of-death sequence was developed for the training and, based on participant inputs, later refined (Fig. 1). On the death of a patient, the clinician first needs to decide whether referral to the Forensic Pathology Service (FPS) is required. For this decision, the guidelines set by the regulations to the National Health $\operatorname{Act}^{[8]}$ and the Health Professions Act ${ }^{[9]}$ are followed. If referral to the FPS is not required, the underlying cause of death should be written on the lowest completed line in Part 1 of the Medical Certificate of Cause of Death section on the DNF. The terminal or immediate cause of death is the final disease or condition that the patient suffered from before death, and should be written on the first line of the cause-ofdeath sequence. ${ }^{[7]}$ The DNF should not contain any mechanisms of death, such as hypoxia, heart failure or cardiac arrest - these are terms that indicate the physiological abnormality in the body at the time of death, but cannot and should not indicate the underlying or immediate cause of death. ${ }^{[7]}$

To facilitate maximal attendance, the training programme was conducted in all provinces, enabling doctors from every district to attend. The guideline and training resources developed for the programme are freely available at http://www.sahealthinfo.org/bod/ deathtraining/guideline.htm

Topics covered included:

- The value of mortality statistics, highlighting that national statistics are compiled from information written on DNFs by doctors, and that good quality statistics can assist managers in adequately planning for healthcare in facilities, districts and provinces

- How to complete the DNF correctly, focusing on the cause-ofdeath section

- Identifying all cases that should be referred to the FPS.

The training also prepared the participants to train at local facilities, and accredited the master trainers to enable allocation of continuing professional development (CPD) points to their trainees. Lectures and group discussions were distributed over 2 days, and participants had to prepare mock presentations as 'homework' on the first evening. The purpose of the homework was to provide an opportunity for revision of the topics covered on day 1 , and to ensure that doctors could communicate this information accurately. In order to be accredited as master trainers, doctors had to obtain a score of at least $80 \%$ in an open-book competency test.

A total of 288 doctors attended 15 training sessions; 178 successfully completed the competency test, and 100 were accredited as master trainers. Subsequently 609 health personnel attended 45 in-hospital training sessions provided by 27 of the master trainers. Of these, 385 doctors had been awarded $\mathrm{CPD}$ points at the time of writing. However, 73 of the 100 accredited master trainers had not commenced any training, despite encouragement to do so.

\section{Lessons learnt from training experience \\ Training}

Clinical managers of hospitals were initially targeted, since they can be held to account for the quality of medical certification in their facility. In addition, they are in a position to instruct doctors to attend in-hospital training sessions. However, it was found that family physicians tended to be more interested and were often good communicators. This cadre may therefore be well suited to provide ongoing training.
Doctors were generally receptive to the training and found it useful. They indicated their willingness to change their practice, notwithstanding some reservations about reporting HIV.

The training workshops were conducted over 2 days. We believe that this contributed to a greater understanding of the important concepts and allowed more time for interactive, practical sessions. We were able to focus on problems that are specific to the national scenario, against the background of the international standard. Aung et al. ${ }^{[10]}$ found that interactive workshops with theoretical and practical components were most effective, and that printed material alone was the least effective in improving the quality of death certification. However, interactive workshops can be costly and labour intensive. In our experience, the length of the workshop impacted on attendance - some doctors were not able to attend the full training because of other responsibilities. This raises the question of whether the training period could have been shortened or divided to allow for practical experience before becoming a trainer. However, an extended training period poses significant logistical challenges.

The WHO has developed an online training tool for International Statistical Classification of Diseases and Related Health Problems, 10th revision (ICD-10) medical certification, which Walker et al. ${ }^{[11]}$ recently evaluated and found easy to use and complete in less than an hour, however, some participants mentioned that group discussions might be useful. It should be noted that our trainees appreciated the opportunity to discuss difficult situations during the training.

\section{Reporting HIV}

At every workshop, doctors raised concerns about reporting HIV on the DNF. These included patient confidentiality, the impact on life insurance or funeral policy claims, and the mistaken belief that reporting HIV is not allowed. The last page of the DNF, which contains the cause-of-death information, is supposed to be confidential and is sent directly to the Department of Home Affairs in a sealed envelope, without any copies of the page being made. However, many doctors told us that envelopes were not always available and expressed concern that family members or funeral undertakers might open the envelope. Some doctors reported instances of insurance companies insisting on a copy of the last page before processing the claim, which appears to act as another disincentive for full disclosure of the causes of death.

In order to address this issue, we had in-depth discussions with the chairperson of the Association of Savings and Investments South Africa (ASISA). He confirmed that all exclusion clauses for HIV were scrapped in January 2005. This means that HIV is treated like other chronic diseases such as diabetes or ischaemic heart disease. Most companies require HIV testing upon application for insurance, and cover will be declined or subscriptions loaded if the applicant tests positive. However, should HIV develop during the term of the contract, insurance will be paid out in the event of death due to HIV. Unfortunately, some insurance companies (covering approximately $5 \%$ of the market) are not members of ASISA and their policies in this regard are not clear (personal communication, Pieter Coetzee, chairperson of ASISA). Further concerns about the impact on insurance claims are addressed in section 14 of the National Health Act, which states that personal information may be disclosed if: $(i)$ a person has consented to it; and (ii) a court order or any law requires that disclosure. ${ }^{[12]}$ Usually when a person takes out a life insurance policy, the insured gives written consent to the insurer, granting the right to access any information needed, especially at death. By doing so, the insured waives his right to privacy, and refusal to do so leads to the person not being insured. 


\section{Completing the Death Notification Form}

Before putting pen to paper, think first

What set off the chain of events that led to death?

$\checkmark$

- Physical or chemical influences on the body:

- Physical effects, e.g. gunshot wounds, blunt force trauma

- Chemical effects, e.g. poisons, drugs, anaphylaxis

- Trauma caused by 'nature' e.g. dog bite, lightning, bee sting

- Complications of trauma, e.g. tetanus, gas gangrene, bronchopneumonia.

- Procedure-related deaths: Section 56 of the Health Professions Act, 56 of 1974.

'The death of a person undergoing, or as a result of, a procedure of a therapeutic, diagnostic or palliative nature, or of which any aspect of such a procedure has been a contributory cause, shall not be deemed to be a death from natural causes.'

- Sudden and unexpected deaths:

- 'Cot deaths' (sudden infant death syndrome)

- Sudden deaths in apparently healthy adults without an obvious reason for the death.

- Omission or comission: Any death, suspected to be due to action or neglect from family, the responsible doctor or others.

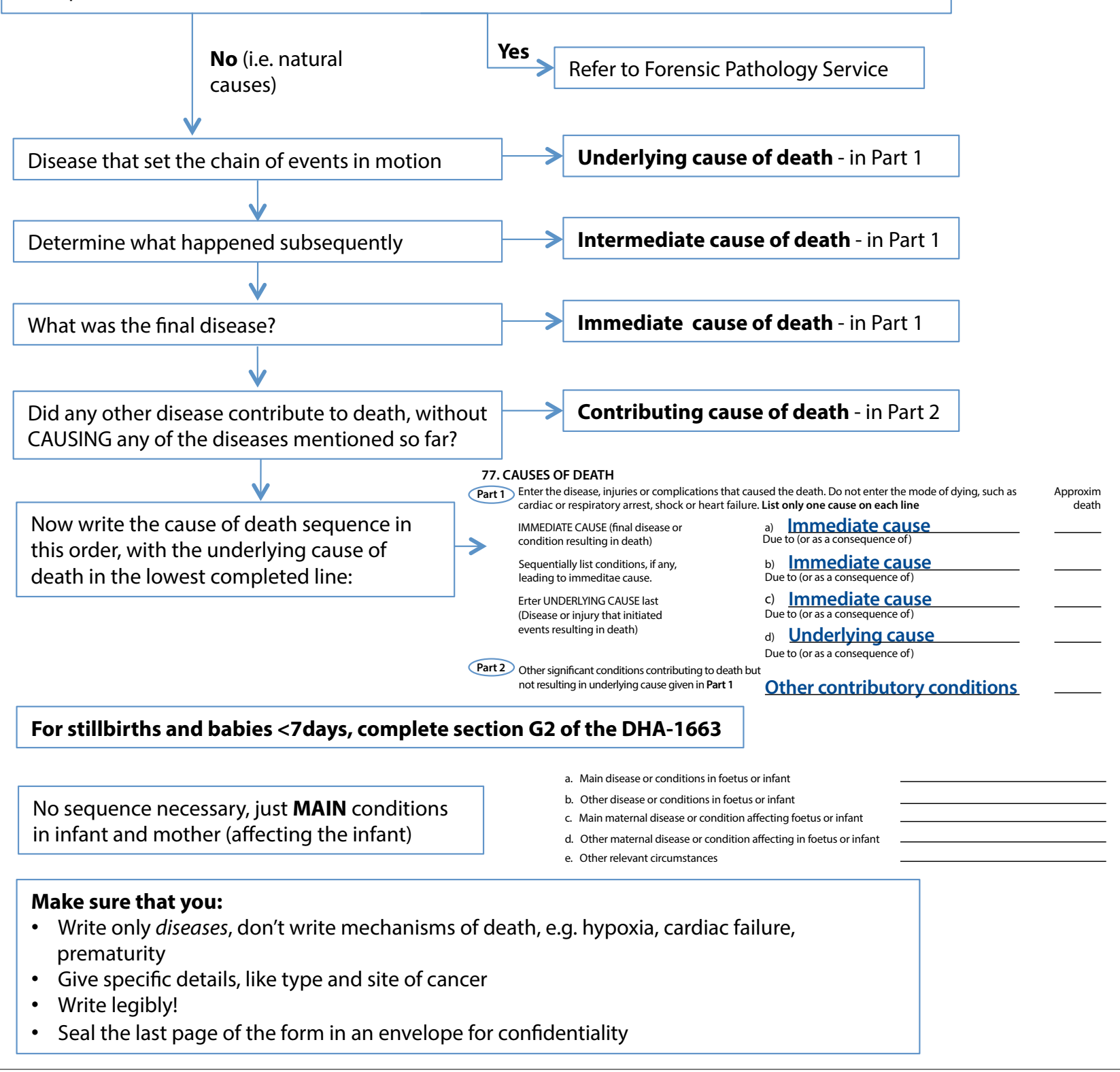

Fig. 1. Completing the Death Notification Form. 
The DNF should be completed truthfully and accurately. The Births and Deaths Registration Act ${ }^{[13]}$ (section 15) places a legal obligation on a medical practitioner to state the known cause of death on the DNF. Making a false statement on the DNF constitutes a criminal offence (section 31). ${ }^{[13]}$

\section{Improving the system/form}

In discussion with participants, it was clear that in many underresourced settings envelopes were not available to seal the last page of the DNF. In the recently released regulations to the Births and Deaths Registration Act, provision is made for the printing of the last page of the DNF on a self-sealing page. This will overcome the problem with envelopes and, it is hoped, encourage full disclosure of the causes of death.

Many doctors admitted to signing DNFs for decedents they had not personally seen. Legally this practice is not acceptable. Recent Health Professions Council of South Africa cases of fraud ${ }^{[14]}$ have highlighted the importance of not signing a DNF for a decedent who was not actually seen. In rural areas where doctors are not available, the DHA-1680 form can be completed for natural deaths by a tribal leader. Furthermore, it is important for hospitals to provide space where doctors can examine the unclothed body of a deceased person to confirm death and the identity of the deceased, and exclude possible injuries that might necessitate referral to the FPS

By law, unnatural deaths must be referred to the FPS. However, feedback from the participants indicated that in some parts of the country, referral to the FPS was problematic and sometimes haphazard. This was due to a perceived lack of resources, poor co-operation from the South African Police Service, and ignorance of the need to refer all possible unnatural deaths.

\section{The way forward}

- A review of our experiences in developing and contributing to the medical certification training programme has identified some key issues that need to be addressed to ensure that SA cause-of-death statistics continue to improve.

- All doctors need to realise the importance and public health utility of accurate cause-of-death data for improving population health, and therefore how important it is to complete the cause-ofdeath section of the DNF correctly. These statistical data inform prioritisation in health policy decisions, budgets and resource allocation, and even influence insurance premiums.

- HIV reporting remains problematic. The Department of Health needs to allay certifying doctors' concerns by providing clear guidance about the legal and public health requirements for accurate reporting of cause of death. In addition, leaders in the insurance industry need to clarify their collective stance on HIV and inform both the public and certifiers of the current policies and their consequences, including that all exclusion clauses for HIV have been scrapped since 2005. Additionally, all doctors should be made aware that making a false statement on the DNF constitutes a criminal offence.
- Some controversy remains among forensic pathologists and legal experts about the legality of indicating the manner of death (circumstances, i.e. homicide, suicide or accident) on the death notification form. Unfortunately, a proposal to include the alleged manner of death on the revised DNF was not accepted in the regulations to the Births and Deaths Registration Act recently gazetted. This uncertainty has to be addressed if useful statistical information about unnatural causes of death is to be obtained.

- Ensuring that doctors certify correctly requires an ongoing systemwide strategy of training and reinforcement. We believe that training in the completion of the DNF should become part of the curriculum in all medical schools, and part of the orientation of interns and community service doctors in all facilities. Regular update sessions for seasoned doctors should also be provided. Academic involvement and support is needed in all regions of the country.

- The development and evaluation of an online medical certification of death training tool with CPD accreditation and helpline support should be a priority.

Acknowledgements. This initiative was sponsored by Statistics South Africa, and the research team worked closely with an interdepartmental task team on Civil Registration and Vital Statistics headed by Dr Maletela Tuoane-Nkhasi of Stats SA. Members of the team include Thomas Sigama, Caroline Pienaar and Kekeletso Rakgotho of the Department of Home Affairs, Thulani Masilela, Mohlapametse Maditsi and Edwina Mabuela of the Department of Health, and Nontsikelelo Manzini-Matebula, Mmamokete Mogoswane, Abram Moyo and Aletia Barkley of Stats SA.

1. Bradshaw D, Kielkowski D, Sitas F. New birth and death registration forms - a foundation for the future, a challenge for health workers? S Afr Med J 1998;88(8):971-974

2. Pillay-van Wyk V, Bradshaw D, Groenewald P, et al. Improving the quality of medical certification of cause of death: The time is now! S Afr Med J 2011;101(9):626.

Burger EH, van der Merwe L, Volmink J. Errors in the completion of the Death Notification Form. S Afr Med J 2007;97(11):1077-1081

4. Joubert J, Rao C, Bradshaw D, et al. Evaluating the quality of national mortality statistics from civil registration in South Africa, 1997-2007. PLoS One 2013;8(5):e64592. [http://dx.doi.org/10.1371/ ournal.pone.0064592

5. Shisana O, Rehle T, Simbayi LC, et al. South African National HIV Prevalence, Incidence and Behaviour Survey, 2012. Cape Town: HSRC Press, 2014.

6. Statistics South Africa. Mortality and Causes of Death in South Africa, 2010: Findings from Death Notification. Statistical release P0309.3. Pretoria: Statistics South Africa, 2013. http://www.statssa.gov. .

za/publications/p03093/p030932010.pdf (accessed 24 February 2014),

World Health Organization. International Statistical Classification of Diseases and Related Health Problems. Vol. 2. 10th revision. Geneva: World Health Organization, 1992.

Regulations to the National Health Act No. 61 of 2003. GN R636 in Government Gazette 30075; 20 uly 2007

9. Health Professions Act No 56 of 1974. http://www.hpcsa.co.za/Uploads/editor/UserFiles/downloads/ legislations/acts/health_professions_ct_56_1974.pdf (accessed 25 November 2014).

10. Aung E, Rao C, Walker S. Teaching cause-of-death certification: Lessons from international experience. Postgrad Med J 2010;86(1013):143-152. [http://dx.doi.org/10.1136/pgmj.2009.089821]

11. Walker S, Rampatige R, Wainiqolo I, Aumua A. An accessible method for teaching doctors about death certification. Health Information Management Journal 2012;41(1):4-10.

12. National Health Act No. 61 of 2003. http://www.saflii.org/za/legis/consol_act/nha2003147/ (accessed 25 November 2014).

13. Births and Deaths Registration Act No. 51 of 1992. http://www.saflii.org/za/legis/consol_act/ badra1992301/ (accessed 25 November 2014).

14. Masombuka S. Death Doctor gets second life. The Times, 23 October 2013, p. 5 